\title{
Who Supports Expanding Surveillance? Exploring Public Opinion of Chinese Social Credit Systems
}

\author{
Chuncheng Liu \\ University of California San Diego \\ chchliu@ucsd.edu
}

Forthcoming in International Sociology.

\begin{abstract}
Pervasive surveillance in modern society has raised mounting debates, which are largely concentrated on the ethical dimension and lack sociological examination. Drawing on innovative national survey data, this study analyzes public opinion about social credit systems (SCSs), an emerging infrastructure that expands the depth and breadth of surveillance in China. I find a general high support for expanding surveillance and punishment yet key variations among different social groups. Counterintuitively, people with higher political capital do not wholly embrace the expanding surveillance and punishment. For example, Chinese Communist Party members are less likely to support state-centered SCSs compared to the general public. Higher political trust in the regime and socioeconomic status is consistently correlated with higher support, while different media consumption showed limited correlations. This study proposes an alternative theorization of surveillance and enriches our understanding of the heterogeneity and dynamic of the state and public in the authoritarian regime.
\end{abstract}

Keywords: Surveillance; Social credit systems; Political capital; Public opinion; China 


\section{INTRODUCTION}

Surveillance is pervasive in society, globally. Although surveillance has only become a widely shared public concern since the Snowden and National Security Agency scandals, it is a perennial topic of interest among sociologists. Giddens (1990), for example, claimed that surveillance, particularly from the state, is a key element of modernity. With the advancement of information and communication technologies in recent decades, surveillance has been expanded in almost every domain in societies. As David Lyon (2018) argues, it has become a culture, a way of life.

State agencies claim that expanded surveillance is necessary for providing social goods. Yet sociologists often follow a critical tradition, seeing surveillance as the mean of control and governance, a key power technique to facilitate the individuals to internalize social norms and form a disciplined subjectivity (Foucault 1995). In other words, state surveillance produces both representation of the reality for the state as well as performative effects on society. These norms are often generated from the standpoint of the state with great symbolic power (Bourdieu 2018), yet also neglecting local needs and contexts of the governed and causing unintended social problems (Scott 1999). In the last decade, scholars have advanced these grand theories by demonstrating how the adoption of new surveillance technologies invades privacy, marginalizes the disadvantaged, and harms political freedom (Brayne 2020; Richards 2012; Xu 2020). These critiques have generated intense debates regarding the normative and ethical aspects of surveillance among the government, public, activists, and scholars. However, empirical studies of how the public perceives them have not been adequately conducted, and sociological studies in this field are even rarer.

We need more studies on what surveillance is, how it operates, and how it is perceived before debating what it should (not) be. While sociologists and social psychologists agree that social norms are perceived and performed differently among different social groups (Tajfel 1981; Kiviat 2021) and have identified how the same surveillance system often differently apply to different populations (Brayne 2020; Liu 2020), current public opinion

studies of surveillance often still take the public homogeneously. Commonly, scholars only examine the relationship between different opinion variables, such as how approval for 
surveillance is associated with disapproval for immigrants. Individual traits, group affiliations, or behavioral characteristics are often absent or only selectively used as control variables without further examination or discussion. Two simple questions are still awaiting answers: Does support for surveillance vary among different social groups? If so, who supports surveillance more than others, and how should we explain these groups?

Furthermore, as scholars from different disciplines have recently pointed out, existing studies on surveillance are highly US- and European-centric despite long-term urges for insights from the Global South (Potoglou et al. 2017; Wood 2009; Ziller and Helbling 2020). Ironically, studies on authoritarian regimes where surveillance is more pervasive and consequential are even rarer $(\mathrm{Su}, \mathrm{Xu}$, and $\mathrm{Cao} 2021)$. This gap is particularly problematic as surveillance practices and perceptions of surveillance are highly contextdependent across different sociopolitical systems (Krueger, Best, and Johnson 2020; Liu and Graham 2021; Lupton and Michael 2017). For example, terrorism concerns heavily impact the public's perception of surveillance in the US and Europe (Reddick, Chatfield, and Jaramillo 2015; Potoglou et al. 2017), while no such effect is observed in countries like China and Japan (Su, Xu, and Cao 2021; Wood 2009). We need more research on nonWestern societies to better understand surveillance both as an important part of these societies and as a part of a more inclusive theory of surveillance in modern society.

This study uses original survey data to examine urban Chinese public opinion about China's social credit systems (SCSs, 社会信用体系), a surveillant assemblage that has raised interest from various fields and ignited heated debates regarding surveillance. I examine how four factors are associated with public support for the state-centered SCSs: political capital, political trust, media exposure, and experiences with SCSs. Counterintuitively, I find that higher political capital does not necessarily mean higher support for SCSs. For example, members of the Chinese Communist Party (CCP), the ruling party of China, are less likely to support state-centered SCSs surveillance and punishment. Meanwhile, higher political trust correlates with higher support for statecentered SCSs. I demonstrate this contrast in the context of the authoritarian political structure, where the relationship between elites and the state is more complicated than a 
simple alliance in against the public. Furthermore, a lack of significant correlation between media exposure and support for surveillance offers insights to understand the current Chinese public sphere. This study provides valuable knowledge about public opinion regarding surveillance and political dynamics in contemporary China, as well as a more nuanced and realistic understanding of the logic and function of state surveillance.

\section{CREDIT SYSTEMS AS SURVEILLANCE}

In recent years, scholars have noted an accelerating expansion of surveillance infrastructures in China (Creemers 2018; Su, Xu, and Cao 2021). Among them, Chinese SCSs have raised the gravest concerns. Credit systems are not Chinese inventions. They are commonly used to deal with information asymmetry in the market, collecting various data to construct models and predict people's creditworthiness and have long been conceptualized as surveillance systems for marketing (Lauer 2020; Marron 2009). State agencies can also utilize the credit system data for specific surveillance use on special occasions, such as COVID-19 contact tracing in South Korea (French and Monahan 2020). Recent scholars have found that consumer credit systems in Western societies have been "off-label" used in unintended situations, such as renting and hiring (Rona-Tas 2017). These systems' wider application results in an increased power to impact social norms and life chances (Fourcade 2021). Being surveilled and evaluated correctly by the credit system in many countries are therefore critical. United States citizens who are excluded from the consumer credit system even mobilized social movements for inclusion (Krippner 2017), while what indicators should be included are contested (Kiviat 2021).

Chinese SCSs, however, is more ambitious and extend the purpose of traditional consumer credit systems. As the State Council (2014) suggested, SCSs are "important parts of the socialist market economy and social governance." Various SCSs have been piloted with different focuses and operationalizations, which can be roughly classified into two categories, market-centered SCS and state-centered SCS (Kostka 2019; Liu 2019). Marketcentered SCSs are the Chinese counterparts of the credit systems in other societies. For example, People's Bank of China, the central bank of China, has a credit report system 
based on bank and financial institution data that is similar to the credit report in the United States and Schufa in Germany. Private tech companies, such as Ant Group and Tencent, also developed their score-based credit systems based on big data that are similar to the FICO score system in United States, such as Zhima credit. These market-centered SCSs, like their western counterparts, are mostly used in financial scenarios such as loaning and share some similar problems such as off-label uses, yet they are in general less controversial.

Another form of the SCS - state-centered SCSs - raised more concerns. State-centered SCSs aim to enhance governance and are developed by different state agencies, from central government agencies to local governments, which has two common forms. The first is blacklist system, which surveil severe law and norm breaking behaviors. For example, Chinese supreme court invented the "Discredited Subject under Enforcement List (DSEL)," which backlists those people who refused to obey the court's decision. The second is municipal SCS developed by municipal governments, producing credit scores for local residents with diverse data sources. Scholars have used government documents and media reports to investigate the structure and implementation of the state-centered SCSs. Studies have found that building on multiple governmental agencies' collaborations, SCSs have greatly expanded the scope of surveillance compared to traditional credit systems (Creemers 2018; Liang et al. 2018). For example, mistreating one's parents and running a red light are included in many municipal SCSs' metrics (Liu 2019). Furthermore, many new punishments have been invented or extended by state-centered SCSs to increase deterrence. For example, people who are put into the DSEL will be punished by having their personal information displayed in public or their travel restricted, along with others. These expanding surveillance and punishment raised serious concerns and heated debates on the state-centered SCSs' relations to the law, privacy, and social norms (Y.-J. Chen, Lin, and Liu 2018; Dai 2020; Sinkkonen 2021).

Similar to the surprisingly silent on surveillance studies, only a few empirical works have examined how SCSs are implemented in society and perceived by the public. Kostka's (2019) groundbreaking research used national survey data to show high support 
for SCSs among the Chinese public: only $1 \%$ of respondents in her national survey disapproved of SCSs. However, as Kostka herself acknowledged, her study has several methodological shortcomings. For example, her survey used a single Likert question to ask about people's general approval for SCS without specifying a precise form or aspect of SCSs. This is problematic because under the name of the Chinese SCS are various different systems that have different goals and operations. Meanwhile, like any surveillant assemblage, SCSs are not about an abstract process of surveilling and being surveilled. Instead, different surveillance systems collect specific data from specific social actors and are used in specific ways (Kiviat 2021; Lupton and Michael 2017). When perceiving a surveillance system, people take these specificities into account and may justify or challenge the surveillance's legitimacy on those grounds (Liu and Graham 2021). As a result, this study constrained the scope to state-centered SCSs. I measured people's opinion on what state-centered SCSs do in two aspects: what items do SCSs surveil and what punishments will be enforced due to SCSs. I used synthetic indicators generated from questions that measured people's opinions. This measurement thus generated more accurate and authentic responses and allowed for a more nuanced analysis of this critical issue.

\section{SUPPORTING SURVEILLANCE AND PUNISHMENT}

Building on current literature on surveillance and public perceptions, this study tests five hypotheses about public support for state-centered SCSs in China. First, studies across different societies have clearly shown that political trust plays a great role in the public's support for state surveillance projects, where higher political trust is associated with higher support for surveillance systems. (Reddick, Chatfield, and Jaramillo 2015; Nakhaie and de Lint 2013; Trüdinger and Steckermeier 2017; Levi and Stoker 2000). Such political trust could include trust in government institutions and political systems, as well as in the enforcement of the surveillance. The only two studies on Chinese public perceptions of surveillance also tested this hypothesis and found a generally positive correlation between trust in government and support for surveillance (Kostka 2019; Su, Xu, and Cao 2021). 
However, both studies only measured people's trust in the general government without variations. As scholars who study trust in China have shown, the Chinese public's political trust toward different political institutions varies depending on the institution's position in the political hierarchy, which requires separate analysis (Li 2016; Wu and Shi 2020).

H1a: People who have higher political trust in the political system in China are more likely to support state-centered SCSs.

H1b: People who have higher political trust in the central government are more likely to support state-centered SCSs.

H1c: People who have higher political trust in the local government are more likely to support state-centered SCSs.

Second, one's political capital may also correlate with one's support for state-centered SCSs. Political capital is an important indicator for differentiating people in authoritarian regimes, as it is often convertible to various capitals and determines one's life chances (Nee 1996; Rona-Tas 1994). In China, one's political capital is commonly conceptualized as one's closeness to the party-state (Nee 1996; Ji and Jiang 2020). In general, studies have found that one's political capital is positively correlated with policy support (J. Chen and Dickson 2008). Scholars have argued that in an authoritarian regime where the power is concentrated, policies commonly benefit people who are closer to the power center more than the ordinary people (Rona-Tas 1994; Zaloznaya 2015), which can explain this positive correlation.

However, we should not equate political capital with specific policy supports. First, members of the ruling party of an authoritarian regime might not be supportive of the expanding surveillance and punishment from the ideological preference. As elite cohesion theories indicate, authoritarian regimes need to include diverse elite stakeholders in their system to ensure its survival (Bray, Shriver, and Adams 2019; Geddes 1999). In an authoritarian country's developing period, elites included in the ruling party are particularly more likely to be ideologically liberal (Atabaki and Zurcher 2004; Mauzy and Milne 2002). CCP itself has shown a great elasticity in its ideological stances since the reform and opening up in the 1980s. Some still join CCP for communist ideological affinity. 
However, people increasingly join the CCP out of the self-interested calculation, such as general career development, and do not necessarily trust or support the political system or specific policies (Dickson 2014). A recent survey showed that CCP members are more politically "liberal" than the masses in many social issues (Ji and Jiang 2020). As a result, CCP members may be less likely to support expanding surveillance.

Meanwhile, it is important to differentiate people with different degrees of political capital. Authoritarian politics scholars often treat people with political capital as two kinds. Those state apparatus officials are classified as the political elite - "cadre" in the Chinese context, as the majority of staff in the state apparatus are CCP members - while the rest as the public. This binary highlights the various privileges a political elite in China entitle. Yet, it those people with some political capital yet not working in the state apparatus invisible. In the Chinese context, those people are, first, those who work in the state sectors, such as public institutions like a public hospital or public school, as well as state-owned enterprises (Jin and Xie 2017; Lin and Bian 1991). Second, as political capital is not only about oneself but also derives from one's social network, particularly one's family network (Nee 1996), those who had political elite relatives also share some political capital yet not with great amount. In both situations, people with some political capitals are different from the public for having unique benefits through their connections to the state, such as better job securities and more economic opportunities (Jin and Xie 2017; Lin and Bian 1991; Nee 1996). They are also different from the political elites for not having the direct political power granted by the state.

This differentiation is particularly important for surveillance perception, as states especially authoritarian party states - do not only need to surveil and discipline their general citizens but also their own bureaucrats, staff, and officials, as well as their social networks (Fukuyama 2004; Giddens 1990). While people with great political capital may benefit from the expanding surveillance and punishment of society, people with only some political capital are less likely to directly benefit from it; in fact, they are often more likely to fall under greater control from this expansion. This different positionality may result in different perceptions of the state's expanding surveillance and punishment. 
H2a: CCP members are less likely to support state-centered SCSs compared with the public.

H2b: People with the highest political capital are more likely to support state-centered SCSs compared with others.

H2c: People with some political capitals are less likely to support state-centered SCSs compared with the public.

Third, the media powerfully influences public perceptions of surveillance and punishment (Reddick, Chatfield, and Jaramillo 2015). For example, Nacos and TorresReyna (2007) showed how media coverage strongly shaped people's perception of Muslims, which facilitated the establishment of surveillance systems in the US. The only study that examines the Chinese context ( $\mathrm{Su}, \mathrm{Xu}$, and Cao 2021) measured information exposure from different forms of media (such as TV, newspaper, or Internet) and found no significant correlation between them and surveillance support. However, the authors assumed information from different forms was homogeneous and did not differentiate what the kinds of information people were exposed to. However, a reader of a foreign newspaper and a reader of a domestic nationalist newspaper are exposed to very different information and have contrasting opinions on the same thing. Although the state controls the domestic media in China, the degree of control among different media differ, and spaces for critical voices do exist (Repnikova 2017). As a result, domestic liberal media and foreign media have different audiences and may sometimes challenge state policy. For example, the domestic liberal media's backlash to the first municipal SCS experiment in Suining in 2010 pushed the government to withdraw the policy in a year (Creemers 2018).

H3a: People who consume information from official media are more likely to support state-centered SCSs.

H3b: People who consume information from domestic liberal media are less likely to support state-centered SCSs.

H3c: People who consume information from foreign media are less likely to support state-centered SCSs. 
Fourth, as previous studies found, people have different imaginations of surveillance regimes that may not necessarily correspond with their perception when they experience them (Lupton and Michael 2017). Scholars on public perception of science and political institutions argue that trust and support for them are commonly built on wishful ignorance, while advancing understanding of how things work may undermine people's trust and support (Giddens 1990; Eyal 2019). This mechanism can also apply to the public perception of surveillance. A study on Chinese citizens' perception of COVID-19 contact tracing shows that people are more likely to support surveillance from the state compared with surveillance from private companies, due to their more direct interaction with company surveillance in daily life (Liu and Graham 2021). While expanded surveillance and punishment may be preferred hypothetically, those people who have explicit interactions with them could be more cautious and hesitant about their expanding power.

H4a: People who experience state-centered SCSs are less likely to support statecentered SCSs.

H4b: People who experience market-centered SCSs are less likely to support statecentered SCSs.

Lastly, studies have shown that the impact of surveillance and punishment on people is uneven. Across diverse social settings, socially disadvantaged people are often under harsher scrutiny, while the privileged may benefit from these new surveillance systems (Brayne 2020; Richards 2012). As a result, people with lower socioeconomic status (SES) might be more hesitant to embrace the expanding surveillance and punishment regime. Kostka (2019) also found that people with higher education and income are more likely to support SCSs. She argued that people with higher SES receive more benefits from SCSs and thus conceptualize SCSs as tools to improve society rather than as surveillance.

H5: People with higher SES are more likely to support state-centered SCSs. 


\section{METHODS}

\section{Research Design}

An online survey for Mainland Chinese urban adult residents was administered by the China Data Lab at UC San Diego between January and April 2020 with the collaboration of Qualtrics, a survey company. Quota sampling based on education, age, residential province, and gender were used to produce a representative sample. Quotas were set up based on each variable's distribution in the urban sample of the 2014 China Family Panel Studies, a widely recognized Chinese national representative survey (Jin and Xie 2017). Qinghai, Ningxia, Xinjiang, and Tibet provinces were not included in the sample due to the hardship of recruitment. Qualtrics sent out invitations to its respondent pool. Once a valid response was recorded, it was counted toward the corresponding quota category. Respondents failing any of these criteria were excluded from the sample and the quota. The China Data Lab paid Qualtrics $\$ 3.5$ per valid response. The survey was approved by the IRB at UC San Diego (\#190190XX). Data were analyzed in R with multivariate linear regressions to identify the correlations.

\section{Dependent Variables}

The key dependent variables in this study were opinions on state-centered SCSs' surveillance and punishment measured by questions using Likert scales. Opinion on statecentered SCSs' surveillance was measured by the mean value of responses to eight questions (Cronbach's Alpha $=0.85$ ). Each question started with "The following options have been included in the SCS in different localities. To what extent do you support these options being part of the SCS?" and then offered the name of the option, such as "misbehavior on the subway." Being part of the SCS means the issue will be surveilled and evaluated by the system. Opinion on state-centered SCSs' punishment was measured by the same approach, using the mean value of a set of responses to seven questions $($ Cronbach's Alpha $=0.78)$. Each question started with "To what extent do you agree that this is an appropriate punishment for people with a bad SCS record?" and then offered the name of the option, such as "restriction on Internet use." All the surveillance and 
punishment options are selected from existing or proposed state-centered SCSs covering different aspects. The option details are listed in Figure 1 and Figure 2, with the reference listed in the appendix A1. For each question, participants could select the answer from strongly oppose (1), somewhat oppose (2), neutral (3), somewhat support (4), and strongly support (5).

Besides the measurement of the supporting degree based on a synthetic metric, I also measured people's state-centered SCS surveillance and punishment supporting scope by calculating how many items a participant gave a supportive response to any question. A supportive response was defined as selecting "somewhat support" and "strongly support." For example, if a participant selected "somewhat support" for including "switching jobs," "strongly support" for including "domestic violence" in the state-centered SCS, and "somewhat oppose" for the rest of the options, her state-centered SCS surveillance and punishment supporting scope score would be 2 . Analysis of these two outcomes is listed in the appendix.

\section{Independent Variables}

Political trust was measured with three variables. First, trust in the Chinese political system was measured using the mean value of responses to seven Likert-scale questions. An example of a question is "In the long run, the Chinese political system can solve the problems facing the country." Participants could select one of the five responses from strongly oppose (1) to strongly support (5). Furthermore, participants' trust in the central government and their residential city's local government was each measured with a scale from 1 to 10.

Political capital was measured with three variables. For an individual, it was measured using their CCP membership (Yes/No) and occupation. Occupation was classified into one of three categories: 1) state apparatus (political institutions such as government and court), conceptualized as having the highest political capital; 2) state sector (public institutions or state-owned enterprises), conceptualized as having middle-level political capital; and, 3) non-state sector, conceptualized as having the lowest political capital. The third measure 
of political capital asked if the participant has relatives working in the state apparatus (Yes/No).

Media consumption was measured with three binary variables: media consumption of official media (People's Daily, Xinhua News, Global Times, or Reference News), domestic liberal media (Caixin, Southern Weekly, or Southern Metropolis Daily), and foreign media (New York Times, Washington Post, or Wall Street Journal). These three binary variables were generated from ten Yes/No questions asking if the participant acquires information from the selected media.

SCSs experiences were measured with the question, "Have you used the following products or services? (Select all that apply)" and response options of Zhima Credit, Tencent Credit, Municipal Credit, People's Bank of China's credit report, or none. People who selected Zhima Credit and/or Tencent Credit were merged into a single category "Commercial Credit System" in data analysis.

Sociodemographic variables include age, gender (male or female), education (below high school, high school and technical school, and college and above), monthly income (below $3000 \mathrm{RMB}, 3001-8000 \mathrm{RMB}$, and above $8001 \mathrm{RMB} ; 1 \mathrm{RMB} \approx 0.15 \mathrm{USD}$ ), and household registration (rural or urban). Every Chinese resident was assigned a household registration (hukou) based on place of birth. The Hukou system classified people into either a rural or urban category, each of which is associated with different social resources and welfare and is, therefore, a significant determinant of social inequality in China (Jin and Xie 2017; Wu and Shi 2020).

Lastly, the survey collected people's reasonings behind their approval and disapproval of SCSs with two "select all that apply" multiple-choice questions, "For the above options that you supported/opposed, what was your reason(s)?" The option details and results are listed in Figure 3 and Figure 4. 


\section{RESULT}

\section{Opinion on Social Credit Systems}

The sample contained 1173 eligible respondents. Detailed information was displayed in appendix A2. The mean overall opinion score for state-centered SCS surveillance was 3.60 , which is above "neutral" and slightly under "somewhat support." "Switching jobs" was the least popular option (mean $=2.75$ ) for state-centered SCSs surveillance; it was also the only option that had a mean score lower than 3 . The most supported option was "misbehavior on the train" (mean = 3.91) (Figure 1). The mean overall opinion score for state-centered SCS punishment was also 3.60. The least favored option was "restriction on children's entry into private schools" (mean $=3.15)$. The most favored option was "disqualified as a civil servant candidate" (mean $=4.09$ ) (Figure 2). In general, this measurement showed a more detailed yet balanced result of public opinion compared with Kostka's (2019) single-question results, where only $1 \%$ of respondents disapproved of SCSs. People see SCSs in a way that is more complex than simple acceptance or rejection.

Among the different factors, those concerns related to the legal system's loopholes and the citizens' inferior $s u z h i^{l}$ were most strongly correlated with higher support for statecentered SCS surveillance and punishment (Figure 3 and Figure 4). This finding indicated that the Chinese public conceptualizes state-centered SCSs as reinforcement for existing legal and moral norms (Dai 2020) rather than as a simple replacement or opposition for the rule of law. Concerns about the unclear nature of SCS rules were most strongly correlated with the lower support for SCS surveillance, which was consistent with findings in the US, where the public's support of surveillance was largely associated with their conception of whether the surveillance could work (Krueger, Best, and Johnson 2020). Concerns about personal freedom had the strongest correlation with the lower support for state-centered SCS punishment. 
Figure 1. Opinions of state-centered social credit systems' surveillance

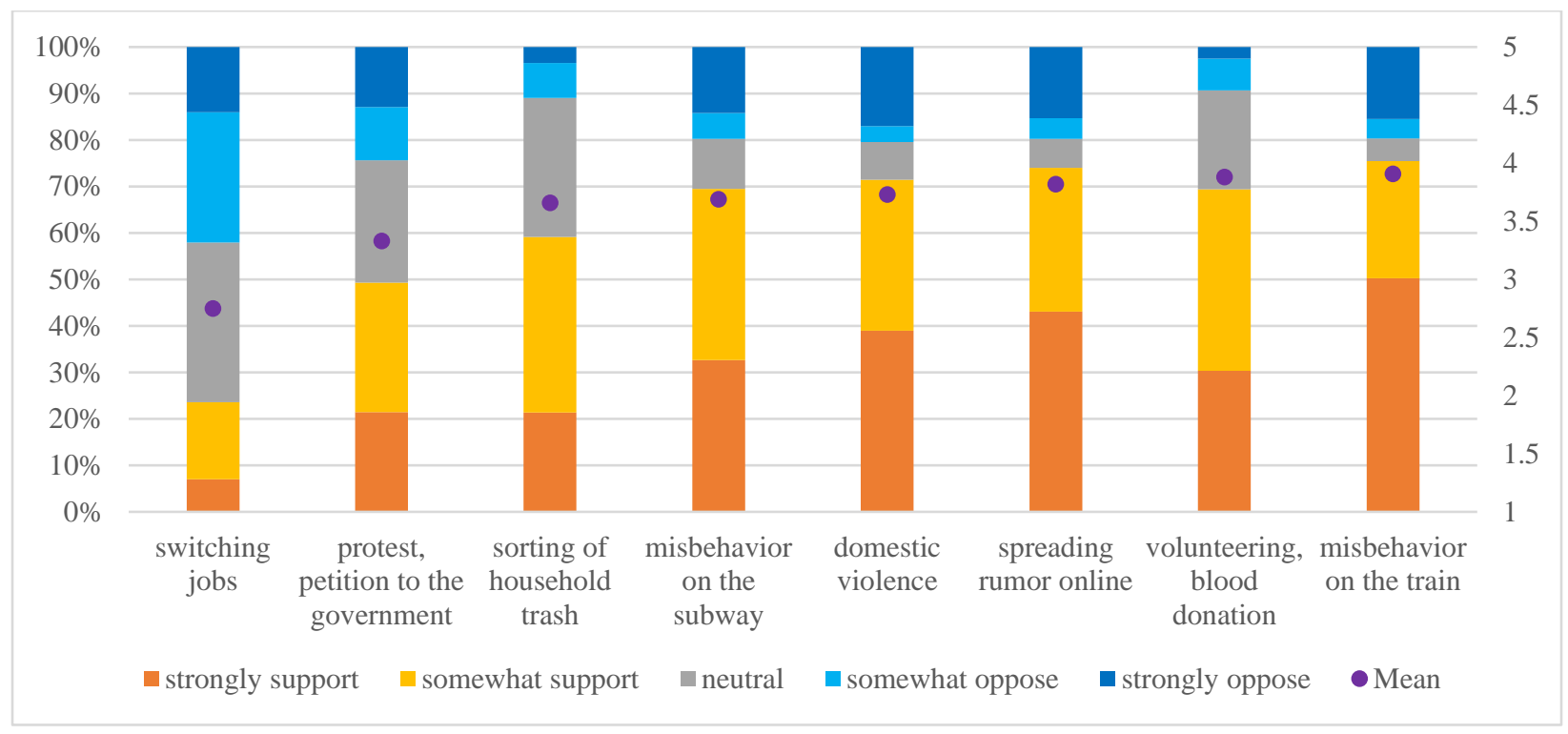

Figure 2. Opinions on state-centered social credit systems' punishment

\begin{tabular}{|rl|l|l|l|}
\hline $100 \%$ \\
$90 \%$
\end{tabular}


Figure 3. Correlation between support for state-centered social credit systems surveillance and reasons for approval and disapproval of social credit systems

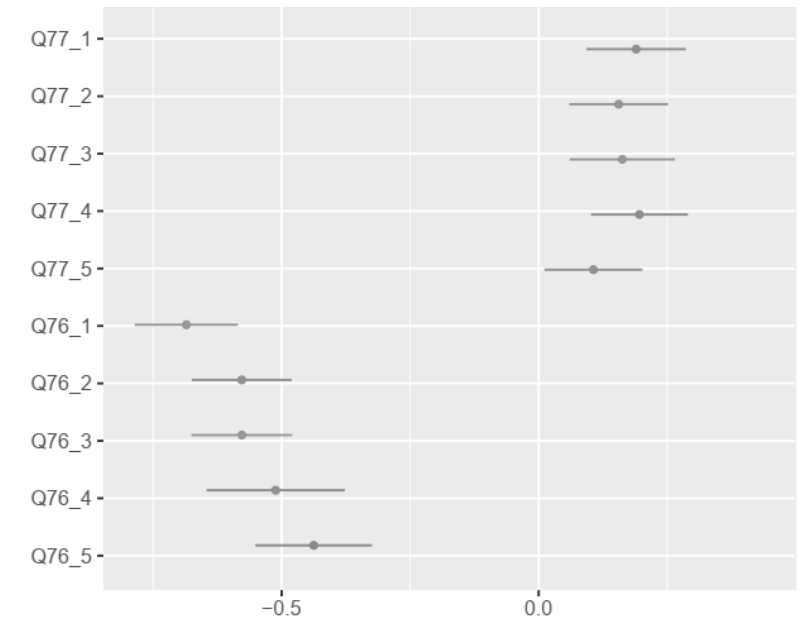

Figure 4. Correlation between support for state-centered social credit systems punishment and reasons for approval and disapproval of social credit systems

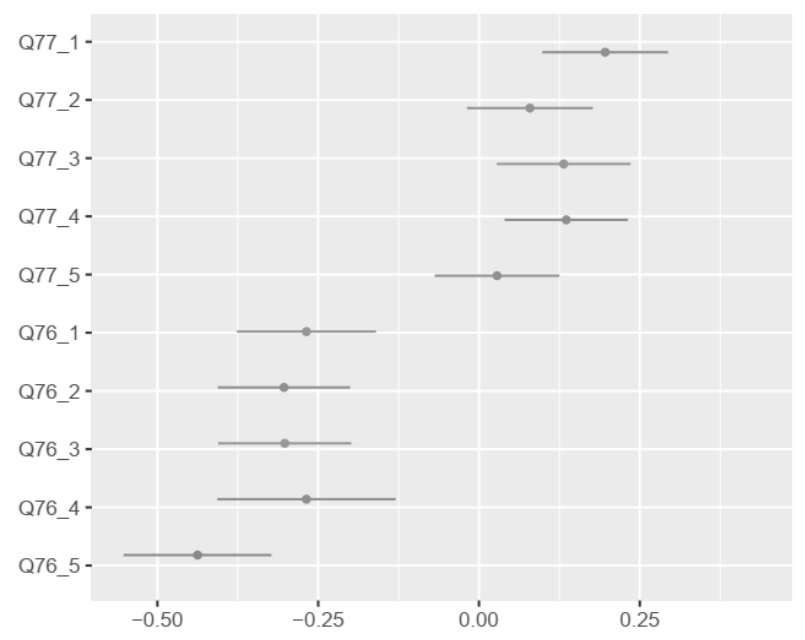

Note: Q76: 1 = unclear rules, difficult to carry out; 2 = potential for abuse; $3=$ privacy issues; $4=$ technical difficulties; $5=$ restriction on personal freedom.

Q77: 1 = citizens have inferior suzhi (human quality), need to be disciplined; 2 = social moral standard is declining, need for stronger rules; $3=$ social stability is declining, need for stronger rules; 4 = legal system has loopholes, need for complementary rules; 5 = for social well-being, individual behavior needs to be disciplined.

Multivariate linear models were used to produce coefficient and 95\% confidence interval with the controlled of age, gender education, income, and hukou status. 


\section{Correlates of Support for Surveillance}

The full results of the multivariate regression models for state-centered SCS surveillance support are detailed in Table 1. Counterintuitively, the political capital was, in general, negatively correlated with support of state-centered SCS surveillance. Being a CCP member $(\beta=-0.149, p<0.05)$ and having relatives working in the state apparatus $(\beta$ $=-0.169, \mathrm{p}<0.01)$ were both negatively correlated with state-centered SCS surveillance support. People working in the state apparatus and non-state sector are both more likely to support SCS surveillance compared with people working in the state sector. In other words, people with middle occupational political capital were the least likely to support statecentered SCSs. This finding persisted throughout different models. In contrast, the correlations between regime support and state-centered SCS surveillance support were generally positive. Both trust in the central government $(\beta=0.057, \mathrm{p}<0.05)$ and trust in the political system $(\beta=0.083, p<0.05)$ were positively associated with support of statecentered SCSs surveillance. Trust in local government negatively correlated with the support for state-centered SCS surveillance, but the absolute value of $\beta$ was small $(<0.01)$ and not statistically significant.

As hypothesized, consumption of information from foreign media $(\beta=-0.124, p<0.05)$ was negatively correlated with state-centered SCS surveillance support. Meanwhile, people who consume information from domestic media, both official $(\beta=0.086)$ and liberal ( $\beta=0.025)$, were more likely to support state-centered SCS surveillance, although no statistical significance was found. SCS-related exposure was negatively associated with support for state-centered SCS surveillance. Both commercial SCS users $(\beta=-0.157, \mathrm{p}<$ $0.05)$ and municipal SCS users $(\beta=-0.196)$ were less likely to support state-centered SCS surveillance, although the statistical significance of the latter disappeared in the final model. People with higher SES - those who had higher income, education level, and urban hukou - were more likely to support state-centered SCS surveillance. Similar patterns of correlations were also observed in the models for the support of state-centered SCS surveillance scope (see appendix A3). 
Table 1 Multivariate regression models of support for state-centered social credit systems surveillance
(1)
(2)
(3)
(4)
(5)
(6)

\section{POLITICAL CAPITAL}

Occupation (Ref: state sector)

State apparatus
Non-state sector
CCP member
Relatives work in the state apparatus
POLITICAL TRUST

$\begin{array}{cc}0.377^{*} & 0.354^{*} \\ 0.071 & 0.053 \\ -0.161^{*} & -0.149^{*} \\ -0.180^{* *} & -0.169^{* *}\end{array}$

Trust in political system

Trust in central government

$\begin{array}{cc}0.075^{+} & 0.083^{*} \\ 0.067^{* *} & 0.057^{*} \\ -0.008 & -0.007\end{array}$

Trust in local government

MEDIA EXPOSURE

Official media

$\begin{array}{cc}0.109 & 0.086 \\ 0.006 & 0.025 \\ -0.167^{* *} & -0.124^{*}\end{array}$

Liberal media

Foreign media

$$
\begin{array}{cc}
-0.249^{*} & -0.196 \\
-0.171^{* *} & -0.157^{*}
\end{array}
$$

Municipal SCS

Commercial SCS

\section{SOCIODEMPGRAHPIC}

\begin{tabular}{lcccccc} 
Age & -0.001 & -0.002 & -0.001 & -0.002 & -0.003 & -0.004 \\
Female & 0.044 & 0.040 & 0.037 & 0.057 & 0.044 & 0.041 \\
Education (Ref: below high school) & & & & & & \\
$\quad$ High school or technical school & 0.057 & 0.055 & 0.058 & 0.056 & 0.050 & 0.052 \\
$\quad$ College and above & 0.062 & 0.085 & 0.104 & 0.066 & 0.064 & $0.126^{+}$ \\
Income (RMB, Ref: below 3000) & & & & & & \\
$\quad$ 3001-8000 & $0.186^{* *}$ & $0.191^{* *}$ & $0.172^{* *}$ & $0.175^{* *}$ & $0.195^{* *}$ & $0.172^{* *}$ \\
$\quad$ Above 8000 & $0.203^{* *}$ & $0.222^{* *}$ & $0.183^{*}$ & $0.230^{* *}$ & $0.235^{* *}$ & $0.241^{* *}$ \\
Urban hukou & $0.284^{* * *}$ & $0.282^{* * *}$ & $0.289^{* * *}$ & $0.289^{* * *}$ & $0.277^{* * *}$ & $0.280^{* * *}$ \\
Constant & $3.187^{* * *}$ & $3.568^{* * *}$ & $2.414^{* * *}$ & $3.133^{* * *}$ & $3.384^{* * *}$ & $2.967^{* * *}$ \\
$N$ & 1,158 & 1,158 & 1,155 & 1,158 & 1,158 & 1,155 \\
$\mathrm{R}^{2}$ & 0.024 & 0.038 & 0.052 & 0.031 & 0.034 & 0.078 \\
Adjusted R $\mathrm{R}^{2}$ & 0.018 & 0.029 & 0.043 & 0.023 & 0.027 & 0.063 \\
\hline
\end{tabular}

${ }^{+} \mathrm{p}<.1 ;{ }^{*} \mathrm{p}<.05 ;{ }^{* *} \mathrm{p}<.01 ;{ }^{* * *} \mathrm{p}<.001$ 


\section{Correlates of Support for Punishment}

The full results of the multivariate regression models for state-centered SCS punishment support are detailed in Table 2. Similar to support for state-centered SCS surveillance, people who were CCP members $(\beta=-0.034)$ or had relatives working in the state apparatus $(\beta=-0.105)$ were less likely to support state-centered SCS punishment. The difference between groups with different occupational political capital was small (the absolute value of $\beta<0.01)$. However, none of the correlations between political capital and support for state-centered SCS punishment were statistically significant. Political trust was positively related to support for state-centered SCS punishment. Those who trust in the Chinese political system more were significantly more likely to support state-centered SCS punishment across models $(\beta=0.138, \mathrm{p}<0.01)$. Trust in both central government $(\beta=$ $0.022)$ and local government $(\beta=0.019)$ was also positively related to higher support for state-centered SCS punishment, although it was statistically insignificant.

Similar to support for state-centered SCS surveillance, people who consume information from domestic media, whether official $(\beta=0.056)$ or liberal $(\beta=0.055)$, were more likely to support state-centered SCS punishment. People who consume information from foreign media were also more likely to support state-centered SCS punishment with a relevantly small $\beta(0.013)$. None of the correlations between media consumption and support for state-centered SCS punishment were statistically significant. In terms of SCSrelated exposure, commercial SCS users $(\beta=-0.174, \mathrm{p}<0.01)$ were less likely to support state-centered SCS punishment. Similar to support for state-centered SCS surveillance, people with higher SES were more likely to support state-centered SCS punishment. Different from support for state-centered SCS surveillance, where no gender difference was found, female participants were statistically less likely to support state-centered SCSs punishment $(\beta=-0.085, \mathrm{p}<0.1)$. Similar patterns were also observed in the models for support of the scope of state-centered SCS punishment, with more statistically significant results (see appendix A4). 
Table 2 Multivariate regression models of support for state-centered social credit systems punishment

$\begin{array}{llllll}(1) & (2) & (3) & (4) & (5) & (6)\end{array}$

\section{POLITICAL CAPITAL}

Occupation (Ref: state sector)

State apparatus

Non-state sector

CCP member

Relatives work in the state apparatus

\section{POLITICAL TRUST}

Trust in political system

Trust in central government

Trust in local government

\section{MEDIA EXPOSURE}

Official media

Liberal media

Foreign media

\section{SCS EXPERIENCES}

Municipal SCS

Commercial SCS

\section{SOCIODEMPGRAHPIC}

Age

Female

Education (Ref: below high school)

High school and technical school

College and above

Income (RMB, Ref: below 3000)

3001-8000

Above 8000

Urban hukou

Constant

N

$\mathrm{R}^{2}$

Adjusted R $\mathrm{R}^{2}$

$\begin{array}{cc}-0.005 & 0.001 \\ -0.085 & -0.010 \\ -0.022 & -0.034 \\ -0.113^{+} & -0.105\end{array}$

$\begin{array}{cc}0.139^{* * *} & 0.138^{* * *} \\ 0.019 & 0.022 \\ 0.028 & 0.019\end{array}$

0.090

0.056

0.059

0.055

$-0.011$

0.013 $\begin{array}{ll}0.130 & 0.073\end{array}$

$-0.184^{* *} \quad-0.174^{* * *}$
$0.009^{* * * *} 0.009^{* * *} 0.009^{* * *} 0.009^{* * *} 0.008^{* * *} \quad 0.008^{* * *}$

$\begin{array}{llllll}-0.052 & -0.055 & -0.076 & -0.057 & -0.057 & -0.085^{+}\end{array}$

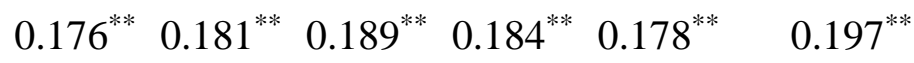

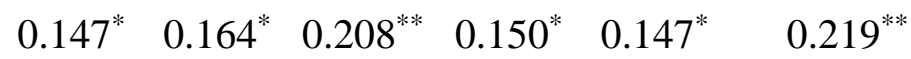

$0.241^{* * * *} 0.242^{* * * *} 0.213^{* *} 0.220^{* *} 0.244^{* * *} \quad 0.206^{* *}$

$0.292^{* * *} 0.298^{* * *} 0.248^{* *} 0.256^{* *} 0.298^{* * *} \quad 0.235^{* *}$

$0.254^{* *} 0.249^{* *} 0.243^{* *} 0.249^{* *} 0.237^{* *} \quad 0.222^{* * *}$

$2.755^{* * *} 2.791^{* * *} 1.925^{* * *} 2.668^{* * *} 2.945^{* * *} \quad 2.120^{* * * *}$

$\begin{array}{llllll}1,158 & 1,158 & 1,155 & 1,158 & 1,158 & 1,155\end{array}$

$\begin{array}{llllll}0.068 & 0.072 & 0.103 & 0.072 & 0.076 & 0.113\end{array}$

$\begin{array}{llllll}0.063 & 0.063 & 0.095 & 0.064 & 0.069 & 0.098\end{array}$

${ }^{+} \mathrm{p}<.1 ;{ }^{*} \mathrm{p}<.05 ;{ }^{* *} \mathrm{p}<.01 ;{ }^{* * *} \mathrm{p}<.001$ 


\section{DISCUSSION}

This study develops new measurements to explore the public opinion of the statecentered SCS's surveillance and punishment in China, showing general high support yet varied attitudes toward different items among different social groups. The most surprising finding is the nuanced relationship between political capital and support for state-centered SCSs. First, members of CCP are less likely to support state-centered SCSs compared with non-CCP members. Second, people who have middle-level political capital are the least supportive of state-centered SCSs, compared with those political elites and the public. These findings urge us to think beyond a common yet simplified understanding of people's ideological and policy preference in an authoritarian party-state, which assumes those who are closer to the party-state are more allied with the official ideology while taking their policy support for granted. On the contrary, this survey supports recent studies' findings, showing how people with political capital - such as CCP members in China - do not blindly support political institutions (Bray, Shriver, and Adams 2019; Dickson 2014) and are sometimes even more ideologically liberal than the masses (Ji and Jiang 2020).

Besides ideological preference, these findings can be the result of practical concerns, which remind us to conceptualize state surveillance beyond the tool of state repression for the powerless. Instead, the state, particularly the authoritarian state where power is more concentrated, needs to surveil not only its citizens, but also its bureaucrats, members, and institutions for control and cohesion (Bray, Shriver, and Adams 2019). Also, for new state surveillance projects, it is practically easier and politically safer to enforce among smaller groups where the state has a higher level of control (Tsai, Wang, and Lin 2021). In China, many surveillance and evaluation infrastructures have already been enforced for people who are close to the party-state before SCSs, such as the Case Quality Assessment System for judges and CCP member evaluation systems (Ng and Chan 2021; Zhou and Lian 2020). Many state-centered SCSs also enforce more discipline for people working in state-related institutions than the general public. For example, besides the municipal SCS that applies to every resident, Rongcheng CCP committee (2019) has an extra metric that only applies to the city's $\mathrm{CCP}$ members, which raises more requirements such as conducting four times 
volunteer activities and gaining more than 5 municipal credit score each year. This kind of tightening control, which has been increasingly institutionalized under Xi's regime since 2012 (Sinkkonen 2021), generates both dissatisfaction and caution of the expanding surveillance regime among those who are close to the power.

Why, then, are government political elites more likely to support SCSs when they are also under stricter surveillance? First, it might simply be the tendency for government staff to be more loyal to the state. Second, this can result from the special rent-seeking and patronage that government staff privilege, a common phenomenon in the authoritarian context (Geddes 1999; Zaloznaya 2015). An analysis of a municipal SCS metric found government staff has more opportunities to gain credits, such as turning their internal honor and awards into booster points (Liu 2020). Government staff is also the main enforcer of the state-centered SCS who entitles certain power that may help them bypass the surveillance and punishment of the system. These opportunities are not available to people working in other sectors and can offset the drawbacks of the state-centered SCSs for the government staff. This results in what I call the "man-in-the-middle effect"- Those who have the middle-level political capital often are under extra scrutiny from the state surveillance projects than the public yet fewer opportunities to gain from or bypass the surveillance compared with the political elites. This effect also resonates with the adoption of new surveillance systems in liberal democracies. For example, in Brayne's (2020) study on the use of big data surveillance technology in policing, she discovered surveillance data became widely repurposed to be data for performance evaluation. People with middle-level power (police officers) also became subject to the new system's surveillance; thus, they are more explicitly dissatisfied with the new system. In contrast, people with more power (management) can bypass the surveillance or benefit more from it as a management tool.

Contrary to the nuance in the relationship between political capital and support for state-centered SCSs is the consistent positive correlation between SES and support for SCSs, which is the same as the previous study (Kostka 2019). Kostka suggested that the different degrees of support could result from different social groups receiving different benefits from SCSs. I argue that this attitude difference could also result from the perceived 
risk and unequal harms of the surveillance and punishment systems. Perceived risks and the moral panic they generate are often important driving forces for people's support to expand surveillance and punishment systems (Wood 2009). Recent studies have shown that higher SES is associated with higher risk awareness and lower trust in others in China (Wu and Shi 2020), which may contribute to the urge to expand society's surveillance and punishment regime. Furthermore, as many scholars have convincingly shown, expansions of surveillance and punishment are often overly enforced on socially marginalized and disadvantaged groups, even when those systems are often claimed to be universal and objective (Brayne 2020; Lyon 2018). This is particularly salient in the difference between people with rural hukou and urban hukou. People migrating from rural to urban areas have long been stigmatized as uncivilized and prone to crime, experiencing social exclusion, victimization, and particular attention from the surveillance regime (Cheung 2013; Murphy 2004). These experiences can transfer to expectations of the new surveillance and punishment system and lower supports.

Exposure to domestic media, in general, also does not have much influence on people's opinion of state-centered SCSs. This could be a result of the Chinese authority's increasing repression of media and civil society in recent years (Creemers 2018; Repnikova 2017). A review of Chinese domestic media reports on SCSs showed that critical voices are extremely rare (Ohlberg, Ahmed, and Lang 2017), in sharp contrast to the vocal backlash domestic liberal media organized to the first state-centered SCS in Suining a decade ago. While foreign media exposure does have a significant correlation, we should remember that most Western media are blocked in China. As a result, people who still acquire information from the Western media are more likely to have a strong motivation and critical stance from the outset. However, the absence of critical public debates does not mean the absence of dissent and problems. This study shows that people who have used SCSs are less enthusiastic about them. This likely results from the conflict between the greater good that people imagine the surveillance and punishment system might bring and their actual experiences - or at least realizations - of themselves being the target. With the 
further expansion of SCSs in society, more people will be directly exposed to their surveillance and punishment. We might observe a decline in supports in the future.

I acknowledge limitations exist in this study. It only samples urban residents via the online channel, while rural residents and people with low SES are under-representative. The quantitative survey also cannot provide important contextual information or identify mechanisms to explain the different levels of support. Chinese SCSs are still under the policy experiment phase and are constantly adjusted, which requires more scholarship to trace and explain their development. I hope that this study sparks new discussions and points out directions for future research about SCSs and other surveillance systems that are pervasive in societies around the globe. This study indicates resists to and changes of SCSs' expanding surveillance and punishment are more likely to be driven by those with the middle-level political capital. First, they have the motivation due to the unsatisfaction and practical concerns. Second, they are more resourceful than other unsatisfied groups with less power to mobilize and leverages over the state, which needs cohesion and co-optation of the elites - not only those political elites - to maintain social order and exercise its power (Geddes 1999; Sinkkonen 2021). Future scholars should retheorize surveillance systems and pay special attention to the politics of those men-in-the-middle to explore the stratified development, function, and meaning of surveillance. Particularly, more qualitative studies of how different groups of people practice and perceive those systems are urgently needed.

\section{ENDNOTE}

${ }^{1}$ Suzhi's literal translation is "quality," indicating a civilized mindset and habitus, or "innate and natured physical, intellectual, and ideological characters of a person" (Murphy 2004, 2) 


\section{REFERENCE}

Atabaki, Touraj, and Erik Jan Zurcher. 2004. Men of Order: Authoritarian Modernisation in Turkey and Iran, 1918-1942. I.B.Tauris.

Bourdieu, Pierre. 2018. On the State: Lectures at the Collège de France, 1989-1992. Hoboken: John Wiley \& Sons.

Bray, Laura A., Thomas E. Shriver, and Alison E. Adams. 2019. "Framing Authoritarian Legitimacy: Elite Cohesion in the Aftermath of Popular Rebellion." Social Movement Studies 18 (6): 682-701. https://doi.org/10/gnjddh.

Brayne, Sarah. 2020. Predict and Surveil: Data, Discretion, and the Future of Policing. Oxford: Oxford University Press.

Chen, Jie, and Bruce J. Dickson. 2008. "Allies of the State: Democratic Support and Regime Support among China's Private Enterpreneurs." The China Quarterly, no. 196: 780-804. https://doi.org/10/bz7kqb.

Chen, Yu-Jie, Ching-Fu Lin, and Han-Wei Liu. 2018. "“Rule of Trust': The Power and Perils of China's Social Credit Megaproject." Columbia Journal of Asian Law 32 (1): 1-36.

Cheung, Nicole W. T. 2013. "Rural-to-Urban Migrant Adolescents in Guangzhou, China: Psychological Health, Victimization, and Local and Trans-Local Ties.” Social Science \& Medicine (1982) 93 (September): 121-29. https://doi.org/10/f5bz8s.

Creemers, Rogier. 2018. "China's Social Credit System: An Evolving Practice of Control." SSRN Electronic Journal. https://doi.org/10.2139/ssrn.3175792.

Dai, Xin. 2020. "Enforcing Law and Norms for Good Citizens: One View of China's Social Credit System Project." Development 63 (1): 38-43. https://doi.org/10/gg32xz.

Dickson, Bruce J. 2014. "Who Wants to Be a Communist? Career Incentives and Mobilized Loyalty in China." The China Quarterly, no. 217: 42-68. https://doi.org/10/f536qj.

Eyal, Gil. 2019. The Crisis of Expertise. Cambridge: Polity.

Foucault, Michel. 1995. Discipline \& Punish: The Birth of the Prison. Translated by Alan Sheridan. Second Edition. New York: Vintage Books.

Fourcade, Marion. 2021. "Ordinal Citizenship.” British Journal of Sociology 72 (2): 152-73. https://doi.org/10.1111/1468-4446.12839.

French, Martin, and Torin Monahan. 2020. "Dis-Ease Surveillance: How Might Surveillance Studies Address COVID-19?" Surveillance \& Society 18 (1): 1-11. https://doi.org/10/ggpt87.

Fukuyama, Francis. 2004. "The Imperative of State-Building." Journal of Democracy 15 (2): 1731. https://doi.org/10/b3wfnp.

Geddes, Barbara. 1999. "What Do We Know About Democratization After Twenty Years?" Annual Review of Political Science 2 (1): 115-44. https://doi.org/10/d7hqsx.

Giddens, Anthony. 1990. The Consequences of Modernity. Polity.

Ji, Chengyuan, and Junyan Jiang. 2020. "Enlightened One-Party Rule? Ideological Differences between Chinese Communist Party Members and the Mass Public." Political Research Quarterly 73 (3): 651-66. https://doi.org/10/ghsqm6.

Jin, Yongai, and Yu Xie. 2017. "Social Determinants of Household Wealth and Income in Urban China." Chinese Journal of Sociology 3 (2): 169-92. https://doi.org/10/ghn7mm.

Kiviat, Barbara. 2021. "Which Data Fairly Differentiate? American Views on the Use of Personal Data in Two Market Settings." Sociological Science 8: 26-47. https://doi.org/10/ghs8zp. 
Kostka, Genia. 2019. "China's Social Credit Systems and Public Opinion: Explaining High Levels of Approval." New Media \& Society 21 (7): 1565-93. https://doi.org/10.1177/1461444819826402.

Krippner, Greta. 2017. "Democracy of Credit: Ownership and the Politics of Credit Access in Late Twentieth-Century America." American Journal of Sociology 123 (1): 1-47. https://doi.org/10/gbmn56.

Krueger, Brian S, Samuel J. Best, and Kristin Johnson. 2020. "Assessing Dimensions of the Security-Liberty Trade-off in the United States.” Surveillance \& Society 18 (1): 104-20. https://doi.org/10/ghpbzt.

Lauer, Josh. 2020. "Plastic Surveillance: Payment Cards and the History of Transactional Data, 1888 to Present." Big Data \& Society 7 (1): 2053951720907632. https://doi.org/10/ggqzrh.

Levi, Margaret, and Laura Stoker. 2000. "Political Trust and Trustworthiness." Annual Review of Political Science 3 (1): 475-507. https://doi.org/10/d3f6n5.

Li, Lianjiang. 2016. "Reassessing Trust in the Central Government: Evidence from Five National Surveys." The China Quarterly 225 (March): 100-121. https://doi.org/10/ghn347.

Liang, Fan, Vishnupriya Das, Nadiya Kostyuk, and Muzammil M. Hussain. 2018. "Constructing a Data-Driven Society: China's Social Credit System as a State Surveillance Infrastructure." Policy \& Internet 10 (4): 415-53. https://doi.org/10.1002/poi3.183.

Lin, Nan, and Yanjie Bian. 1991. "Getting Ahead in Urban China." American Journal of Sociology 97 (3): 657-88. https://doi.org/10/cn4xkq.

Liu, Chuncheng. 2019. "Multiple Social Credit Systems in China." Economic Sociology: The European Electronic Newsletter 21 (1): 22-32. . 2020. "Seeing like a Social Credit System: An Examination of a Chinese Municipal Surveillance Policy Infrastructure." In 32nd Annual Meeting. SASE.

Liu, Chuncheng, and Ross Graham. 2021. "Making Sense of Algorithms: Relational Perception of Contact Tracing and Risk Assessment during COVID-19." Big Data \& Society. https://doi.org/10.1177/2053951721995218.

Lupton, Deborah, and Mike Michael. 2017. “'Depends on Who's Got the Data': Public Understandings of Personal Digital Dataveillance." Surveillance \& Society 15 (2): 254-68. https://doi.org/10/gg2m2x.

Lyon, David. 2018. The Culture of Surveillance: Watching as a Way of Life. 1 edition. Cambridge, UK Medford, MA: Polity.

Marron, D. 2009. Consumer Credit in the United States: A Sociological Perspective from the 19th Century to the Present. Springer.

Mauzy, Diane K., and Robert Stephen Milne. 2002. Singapore Politics Under the People's Action Party. Routledge.

Murphy, Rachel. 2004. "Turning Peasants into Modern Chinese Citizens: 'Population Quality' Discourse, Demographic Transition and Primary Education." The China Quarterly 177 (March): 1-20. https://doi.org/10/dp7nnw.

Nacos, Brigitte Lebens, and Oscar Torres-Reyna. 2007. Fueling Our Fears: Stereotyping, Media Coverage, and Public Opinion of Muslim Americans. Rowman \& Littlefield.

Nakhaie, Reza, and Willem de Lint. 2013. "Trust and Support for Surveillance Policies in Canadian and American Opinion." International Criminal Justice Review 23 (2): 149-69. https://doi.org/10/ghsqmb.

Nee, Victor. 1996. "The Emergence of a Market Society: Changing Mechanisms of Stratification in China." American Journal of Sociology 101 (4): 908-49. https://doi.org/10/fhvfbh. 
Ng, Kwai Hang, and Peter C H Chan. 2021. “What Gets Measured Gets Done': Metric Fixation and China's Experiment in Quantified Judging." Asian Journal of Law and Society.

Ohlberg, Mareike, Shazeda Ahmed, and Bertram Lang. 2017. "Central Planning, Local Experiments.” Berlin: METRIC China Monitor.

Potoglou, Dimitris, Fay Dunkerley, Sunil Patil, and Neil Robinson. 2017. "Public Preferences for Internet Surveillance, Data Retention and Privacy Enhancing Services: Evidence from a Pan-European Study." Computers in Human Behavior 75 (October): 811-25. https://doi.org/10/ghn3zq.

Reddick, Christopher G., Akemi Takeoka Chatfield, and Patricia A. Jaramillo. 2015. "Public Opinion on National Security Agency Surveillance Programs: A Multi-Method Approach." Government Information Quarterly 32 (2): 129-41. https://doi.org/10/f7b36r.

Repnikova, Maria. 2017. Media Politics in China: Improvising Power under Authoritarianism. Cambridge: Cambridge University Press. https://doi.org/10.1017/9781108164474.

Richards, Neil M. 2012. "The Dangers of Surveillance.” Harvard Law Review 126: 1934.

Rona-Tas, Akos. 1994. "The First Shall Be Last? Entrepreneurship and Communist Cadres in the Transition from Socialism." American Journal of Sociology 100 (1): 40-69. https://doi.org/10/cht7sd. . 2017. "The Off-Label Use of Consumer Credit Ratings." Historical Social Research 42 (1): 52-76.

Rongcheng Municipal Party Committee Organization Department. 2019. Implementation Measures for the Credit Management of Urban Community Residents and Active Party Members in Rongcheng City.

Scott, James C. 1999. Seeing like a State: How Certain Schemes to Improve the Human Condition Have Failed. New Haven, Conn.: Yale University Press.

Sinkkonen, Elina. 2021. "Dynamic Dictators: Elite Cohesion and Authoritarian Resilience in China." In The Routledge Handbook of Chinese Studies, edited by Chris Shei and Weixiao Wei, 113-26. Routledge. https://doi.org/10.4324/9780429059704-8.

State Council of China. 2014. Planning Outline for the Construction of a Social Credit System (2014-2020).

$\mathrm{Su}$, Zheng, Xu Xu, and Xun Cao. 2021. "What Explains Popular Support for Government Monitoring in China?" Journal of Information Technology \& Politics 0 (0): 1-16. https://doi.org/10/gnshj6.

Tajfel, Henri. 1981. Human Groups and Social Categories: Studies in Social Psychology. Cambridge Cambridgeshire; New York.

Trüdinger, Eva-Maria, and Leonie C. Steckermeier. 2017. "Trusting and Controlling? Political Trust, Information and Acceptance of Surveillance Policies: The Case of Germany." Government Information Quarterly 34 (3): 421-33. https://doi.org/10/gcrqck.

Tsai, Wen-Hsuan, Hsin-Hsien Wang, and Ruihua Lin. 2021. "Hobbling Big Brother: Top-Level Design and Local Discretion in China's Social Credit System." The China Journal 86 (May): 1-20. https://doi.org/10/gjv7mr.

Wood, David Murakami. 2009. "The 'Surveillance Society': Questions of History, Place and Culture." European Journal of Criminology 6 (2): 179-94. https://doi.org/10/cpsc3q.

Wu, Cary, and Zhilei Shi. 2020. "Education and Social Trust in Transitional China." Chinese Sociological Review 52 (2): 115-43. https://doi.org/10/ghrx62.

$\mathrm{Xu}, \mathrm{Xu}$. 2020. "To Repress or to Co-Opt? Authoritarian Control in the Age of Digital Surveillance." American Journal of Political Science. https://doi.org/10/ggwk99. 
Zaloznaya, Marina. 2015. "Does Authoritarianism Breed Corruption? Reconsidering the Relationship Between Authoritarian Governance and Corrupt Exchanges in Bureaucracies." Law \& Social Inquiry 40 (02): 345-76. https://doi.org/10/f7fb69.

Zhou, Xueguang, and Hong Lian. 2020. "Modes of Governance in the Chinese Bureaucracy: A 'Control Rights' Theory." The China Journal, 000-000. https://doi.org/10/gg2c22.

Ziller, Conrad, and Marc Helbling. 2020. "Public Support for State Surveillance." European Journal of Political Research. https://doi.org/10/ghn35p. 


\section{Acknowledgment}

I am thankful to Margaret Roberts, Lei Guang, Jiannan Zhao, and Eddie Yang for their help with the survey data. Kevin Lewis, Bernardo Mackenna, Ke Nie, Akos Rona-Tas, Zheng Fu, and Marianne von Blomberg offered constructive feedback to the manuscript for which I am grateful. The online survey is part of the "China from the Ground Up" project under the auspices of the China Data Lab at UC San Diego, supported by the Carnegie Corporation of New York, Henry Luce Foundation, and private donors to the 21st Century China Center. 